\title{
EARTHQUAKE RELOCATION IN GREECE USING A UNIFIED AND HOMOGENIZED SEISMOLOGICAL CATALOGUE
}

\author{
Karakonstantis A. ${ }^{1}$ and Papadimitriou P. ${ }^{1}$ \\ ${ }^{1}$ National and Kapodistrian University of Athens, Department of Geology-Geoenvironment, Laboratory of \\ Seismology,Ilisia,Zografou, 15784 -Greece,akarakon@geol.uoa.gr,ppapadim@geol.uoa.gr
}

\begin{abstract}
In this study phase data from the Cornet seismological network installed by the Geophysics-Geothermics Department (University of Athens) and the permanent networks of the Geodynamic Institute of the National Observatory of Athens and of the Geophysics Department of Thessaloniki (Aristotle University), for the decade 1996-2006, were merged. The data were jointly used to relocate the earthquakes that occurred in the broader area of Greece. Initially, single-event algorithms were applied by minimizing spatiotemporal residuals. Following, the hypocenters were relocated using a doubledifference algorithm where rms, as well as the horizontal and vertical location errors (erh, erz) were minimized and a consequence of that better locations were achieved. After that process the spatial distribution of the epicenters outlined major local tectonic features in Greece. Moreover, the same methodology was applied to the aftershock sequences of large earthquakes and the results were successfully compared with those obtained by available local networks that were deployed.
\end{abstract}

Key words: earthquake relocation, homogenized seismological catalogues, seismotectonics, Greece.

\section{Introduction}

The determination of seismotectonic characteristics was a difficult procedure before the commencement of the Hellenic Unified Seismological Network (HUSN) in 2007, and that's because of not sufficient initial phase data that each Institute used. The geometry and the density of each network allowed researchers to locate earthquakes better in some regions than in others. A result of that procedure was the determination of different catalogues, in terms of hypocenter location and quality of the final solution. That could not facilitate us in order to make certain conclusions for seismotectonics in areas where an earthquake sequence occurred or the frequency of background seismicity was high. In this case merging phase data from three institutes (University of Athens, Geodynamic Institute of National Observatory of Athens and Aristotle University of Thessaloniki) was considered necessary in order to achieve azimuthal coverage with seismological stations and better hypocenter locations with single-event algorithms. Besides the previous factors that were mentioned, also the lack of a reliable 1-D layered velocity model per area is a common factor that produces important residuals in body wave arrivals. In this case of study, a double difference algorithm (hypoDD) has been applied to the phase data, targeting the hypocenter relocation of the merged catalogue for the decade 1996-2006 in Greece. Residuals between observed and theoretical traveltime differences (or double-differences) are minimized for pairs of earthquakes at each station while linking together all observed event-station pairs (Waldhauser and Ellsworth, 2000). 

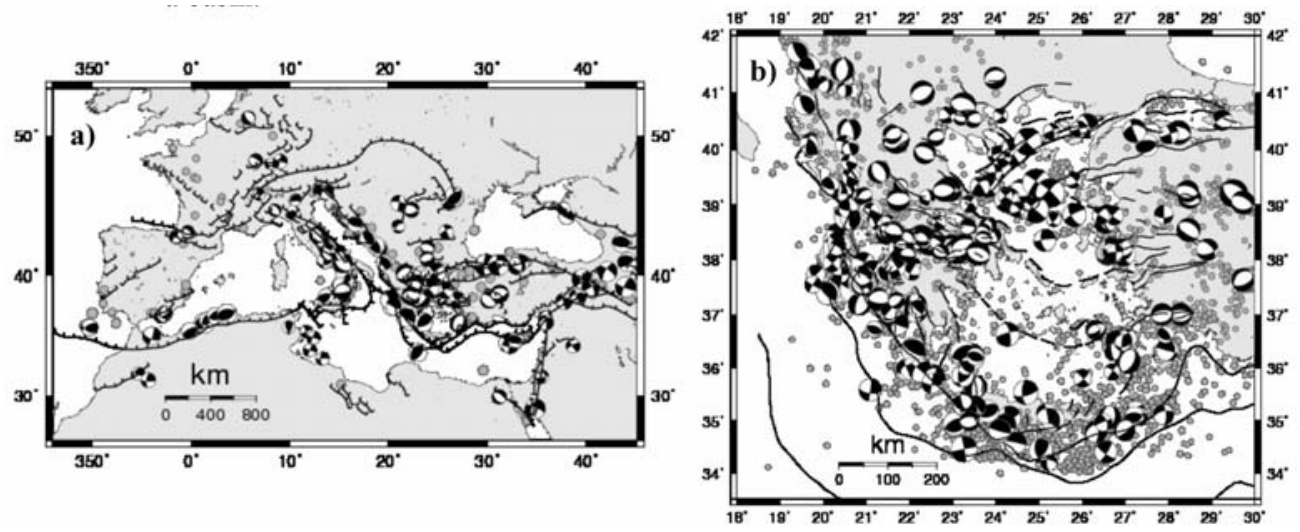

Fig. 1: a) Main faults in the broader area of Europe and significant earthquakes (CMT solutions) b) Main rupture zones in the area of Greece with focal mechanism solutions of significant earthquakes between 1996 and 2006 determined by S-L of UoA, NOA-G.I, A.U.TH, I.N.G.V.

From the whole data set that was processed, three areas will be presented in this case of study that include aftershock sequences of Athens 1999, Skyros 2001 and the background seismicity of Mygdonia basin.

Greece is located to the eastern end of Europe where a variety of geological procedures take place such as the Alpine orogenesis. The creation of the Alpine mountain chain, which is one of the most important geological features, is caused by the collision between Europe and Africa (Fig.1a). Furthermore, an intense deformation observed in Greece and surrounding areas produces important seismicity concentrated in certain seismic zones, such as the Hellenic Arc, characterized by subduction, the North Aegean, dominated by dextral strike-slip faulting, and the back arc area dominated by normal faults (Fig.1b).

Two main fault systems, the Hellenic Trench and the North Aegean Trough, dominate the Eastern Mediterranean, while the majority of the seismicity is located along these tectonic zones. In Fig.1a epicenters as well as focal mechanisms of large $(M \geq 5.8)$ earthquakes throughout Europe are presented. Earthquakes and focal mechanisms with magnitude $M \geq 4.0$ in the Hellenic peninsula and surrounding areas are shown in Fig.1b. Earthquakes with magnitude greater than 6 for the time period 1900-2008 are shown with triangles. Similar focal mechanism solutions are observed in some regions as the Ionian Sea, the North Aegean and the Corinth Gulf. On the contrary, in other areas, as south of Crete, different fault plane solutions appear. Three main types of focal mechanisms can be distinguished: a.) dextral strike-slip motion in the vicinity of the Cephallonia-Lefkas, NW Peloponnesus and North Aegean areas, b.) reverse faulting southern of the Ionian islands and along the Hellenic arc and c.) Normal faulting in the back-arc region.

\section{Data and analysis}

\subsection{Data sources}

Data from three different seismological networks were used to form a joint catalogue that would supply better source parameters. The used earthquake catalogues were the ones of the Department of Geophysics of the National and Kapodistrian University of Athens (Cornet network), the Institute of Geodynamics of the National Observatory of Athens and the Department of Geophysics of the Aris- 
Table 1. Number of earthquakes per network per year.

\begin{tabular}{|c|c|c|c|c|}
\hline Year/Catalogue & Merged Catalogue & CORNET & G.I-N.O.A & A.U.TH \\
\hline 1996 & 3843 & 799 & 2560 & 2783 \\
\hline 1997 & 5407 & 2087 & 3228 & 3219 \\
\hline 1998 & 4380 & 788 & 2866 & 2086 \\
\hline 1999 & 3942 & 710 & 1646 & 1438 \\
\hline 2000 & 4115 & 742 & 3200 & 1488 \\
\hline 2001 & 4136 & 751 & 3040 & 1873 \\
\hline 2002 & 3239 & 472 & 2550 & 1121 \\
\hline 2003 & 4035 & 382 & 6392 & 1709 \\
\hline 2004 & 4987 & 399 & 3333 & 2662 \\
\hline 2005 & 6481 & 178 & 5465 & 2139 \\
\hline 2006 & 6383 & 463 & 5037 & 2797 \\
\hline total & 50.948 & 7771 & 39317 & 23315 \\
\hline
\end{tabular}

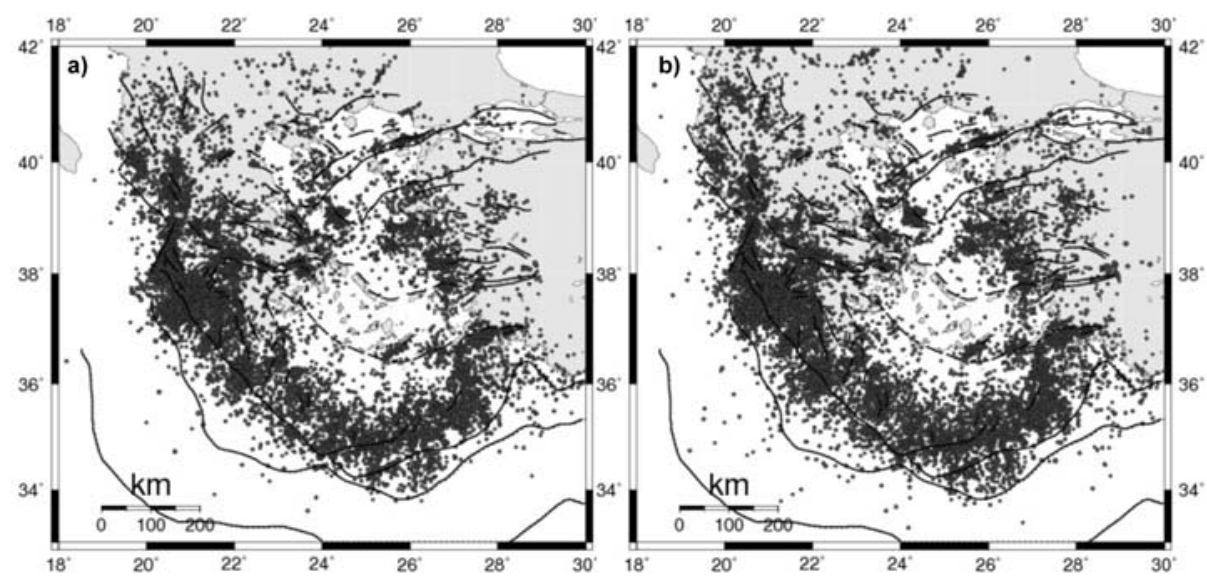

Fig. 2: Located seismicity ( $\mathrm{M} \geq 3.2)$ from a) G.I-N.O.A b) Unified-Homogenized Catalogue.

totle University of Thessaloniki. The joint catalogue includes data from 1996, where the CorNet seismological network started its operation until 2006. By 2004 the first stations of the AtheNet seismological network started to operate, while the Hellenic Unified Seismological Network (HUSN) became operational in 2007. Figure 2 ( $a$ and $b$ ) shows the located seismicity of the GI-NOA and the merged catalogue respectively, while in Table 1 the statistics of the joint and the sub-catalogues are presented.

Each seismological network has its benefits depending on the quantity, geometry and location of the stations. Networks such as Cornet provided better locations for earthquakes that occurred in or near the Eastern Corinth Gulf while the respective network of AUTH enriched the catalogue with welllocated events that occurred in Northern Greece. On the other hand the geometry of NOA's seismological network provides a more representative earthquake distribution. Using data from ATHU, 
NOA and AUTH networks better results are achieved for earthquakes that occurred in the study area, because of the larger number and better distribution of stations. Merging the data from these different sources, a better location of epicenters can be achieved, by reducing the spatial and temporal (rms) errors. Specifically, the joint catalogue contains 50.948 events of magnitude greater than $1.8\left(\mathrm{M}_{\mathrm{D}}\right)$, in the area between $34^{\circ}-42^{\circ} \mathrm{N}$ and $19^{\circ}-29^{\circ} \mathrm{E}$, with mean rms equal to 0.67 seconds and respective mean spatial errors $5.9,5.7$ and $13.3 \mathrm{~km}$ (erx, ery, erz).

\subsection{Merging and homogenizing the phases of different catalogues}

After the collection of phase-arrival data from the three institutes, a process took place, in three main steps:

- Merging phase data, of these three different catalogues, identifying the earthquakes that were recorded by stations of more than one network and completing the joint catalogue by adding the "single-network" events. This process was done manually by comparing the arrival times of the different network stations that were mentioned previously. The catalog magnitudes were calculated using the signal duration $\left(\mathrm{M}_{\mathrm{D}}\right)$.

- The result was an input file of phase arrivals for a single-event program such as HYPO71 or HYPOINVERSE. By re-weighting the $\mathrm{P}$ and the $\mathrm{S}$ phases and applying a 1-D layered velocity structure, we achieved an improvement of temporal and spatial residuals. The velocity model concludes 7 layers in $0,4.2,7,11.5,16.5,35$ and $80 \mathrm{~km}$ depth with respective velocities of 4.8, 5.7, 6.1, 6.3, 6.5, 7.8 and $8.1 \mathrm{~km} / \mathrm{sec}$ (Kaviris, 2003). In HYPO71 the phase arrival was weighted as " 4 " (not taken into account) beyond $400 \mathrm{~km}$, while in HYPOINVERSE there has been a progressive reduction of phase weight from 1 to 0 (100\%-0\%) from 50 to 400 $\mathrm{km}$. The results are shown in Fig.2 for the decade 1996-2006.

- The final catalogue obtained by this procedure was processed by the HYPODD double-difference algorithm (Waldhauser and Ellsworth, 2000), where, as it will be mentioned in a next paragraph, the residuals were minimized. As a result hypocenter locations were ameliorated and alignment of epicenters with main rupture zones of the studied areas was achieved.

The merged input data file was divided in sub-areas, where the algorithm could give better results. These sub-areas were selected using certain criteria such as:

- The distribution of surface mapped rupture zones.

- The Map of seismic sources of surface earthquakes designed by Papaioannou and Papazachos (2000).

- The epicenter distribution through this time period.

Generally the mean spatial errors for the "common" earthquake events of the joint catalogue varied from 1.2 to $4.5 \mathrm{~km}$ (erx and ery) and 4.5 to $8 \mathrm{~km}$ (erz).

\subsection{Double-Difference algorithm (HypoDD)}

HYPODD (Waldhauser and Ellsworth, 2000) is an algorithm that minimizes residuals between observed and calculated travel time differences (or double-differences) for pairs of neighboring earthquakes at each station that recorded both events, as it can be seen from eq. 1. In this way errors caused by unmodeled velocity structure are minimized without the use of station corrections. A minimum 1D layered velocity model is used to predict the travel time differences and partial derivatives (eq. 2). 


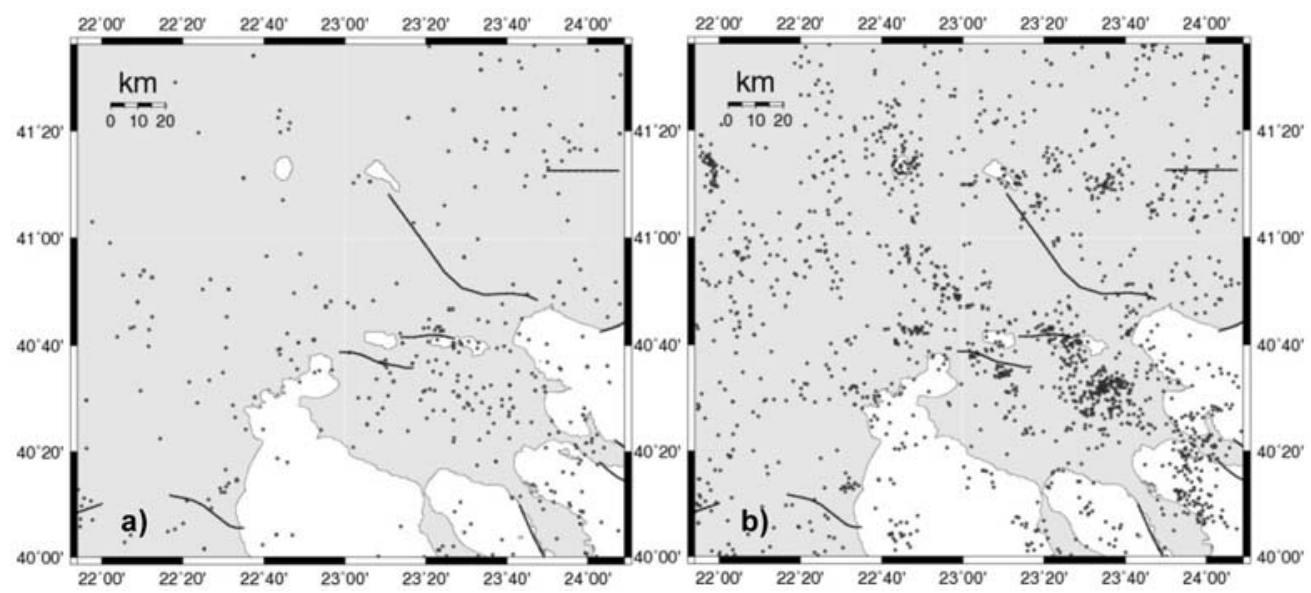

Fig. 3: a) Initial catalogue data of G.I-N.O.A b) Final Catalogue of unified homogenized data for Central Macedonia region $(\mathrm{M} \geq 2.0)$.

(eq.1)

Where $\mathrm{m}=(\mathrm{x}, \mathrm{y}, \mathrm{z})(\mathbf{e q} .2)$

Inter-event distance and misfit weighting is applied after each iteration to catalogue data, to optimize their quality dynamically during relocation. Horizontal and vertical relative spatial errors can be minimized by approximately one order of magnitude under certain conditions.

In this case of study more than 28.000 events of $M_{D} \geq 2.0$, throughout Greece, were relocated with hypoDD. The data set will be uploaded to the site of the Seismological Laboratory of the University of Athens after the final processing and verification. Throughout the areas where the relocation procedure has taken place, a different approach of defying "strong links" was adopted. The main factors that had been taken into account were the size of the dominant clusters, the network coverage of the area, and the occurrence of an aftershock sequence that could reduce the maximum separation distance in ph2dt input parameter file.

\section{Results}

The procedure of merging phases and homogenization through single-event algorithms contributed to the enrichment of the initial catalogue data especially in regions with apparent low rates of seismicity. An ideal example is in the region of Central Macedonia, in Mygdonian basin. From a few tens of earthquakes that were recorded from G.I-N.O.A (Fig. 3a) the final catalogue reached 760 seismic events with $M \geq 2.0$, because of the addition of data from stations of AUTH's seismological stations in the region (Fig.3b). The case of Attica should be considered similar where a great part of the 1999 aftershock sequence was recorded by Cornet seismological network (Fig. 7b) and the joint catalogue's recorded events rose up to $30 \%$. Partially, this conclusion seems to fit in the aftershock sequence of July 2001 as well (Skyros earthquake) where the northern cluster appears to be enriched with more earthquakes (Fig.5b) than the respective from the initial catalogue (Fig. 5a). 


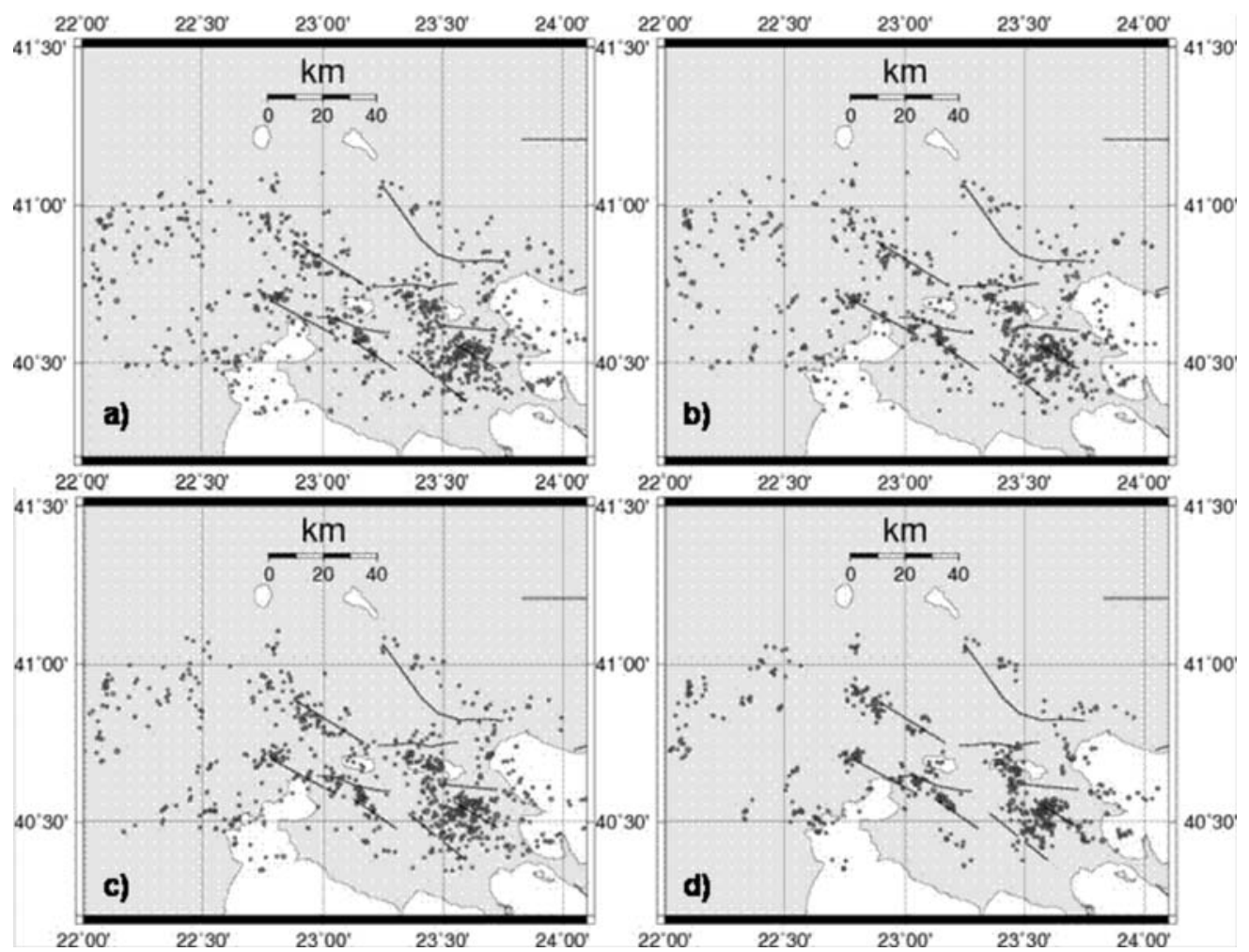

Fig. 4: a) Located earthquakes with HYPO71 b) Relocated data with HYPODD c) Located events with HYPOINVERSE d) Relocated events with HYPODD using a HYPOINVERSE processed primary catalogue $(\mathrm{M} \geq 2.0)$.

Besides the necessity of using merged data from all institutes in this kind of cases that reveals the importance of the National Seismological Network, what should also be emphasized, according to the relocation results, is the need of good initial data quality. As shown in figures 4,6 and 8 the unified and homogenized catalogue data which were processed with HYPOINVERSE produce much better results during the relocation stage than the respective that were processed by HYPO71. This means that the choice of a single-event algorithm should be done carefully by taking into account all the possible aspects (advantages/disadvantages). Specifically, a single-event algorithm such as HYPOINVERSE shows its advantages during the processing of events that are located within the seismic network array while HYPO71 shows more reliable results for epicentres that lie outside of it.

In the area of Mygdonian Basin, 701 out of 760, located with HYPO71, events of the background seismicity $(M \geq 2.0)$ were relocated with HYPODD, giving a first result that could be rated as satisfactory. The mean temporal errors (rms) were reduced from $0.50 \mathrm{sec}$ to $0.14 \mathrm{sec}$ while the spatial errors (erx, ery, erz) were increased from 2.5,2.5 and $5.3 \mathrm{~km}$ to $3.7,3.6$ and $6.3 \mathrm{~km}$ respectively. These data were also processed by HYPOINVERSE, where 697 events were relocated with HYPODD in an even better location. The mean temporal residual (rms) that was determined by HYPOINVERSE was 0.29 seconds while the respective one obtained by the relocation process was 0.11 seconds. During the step of hypocenter location with HYPOINVERSE the spatial errors reached 1.7, 1.8 and $7.9 \mathrm{~km}$ (erx, ery, erz). The respective spatial errors obtained by the relocation with the double-difference algorithm (HYPODD) were 1.7, 1.8 and $2.7 \mathrm{~km}$ (erx, ery, erz). This way it can be clearly seen 


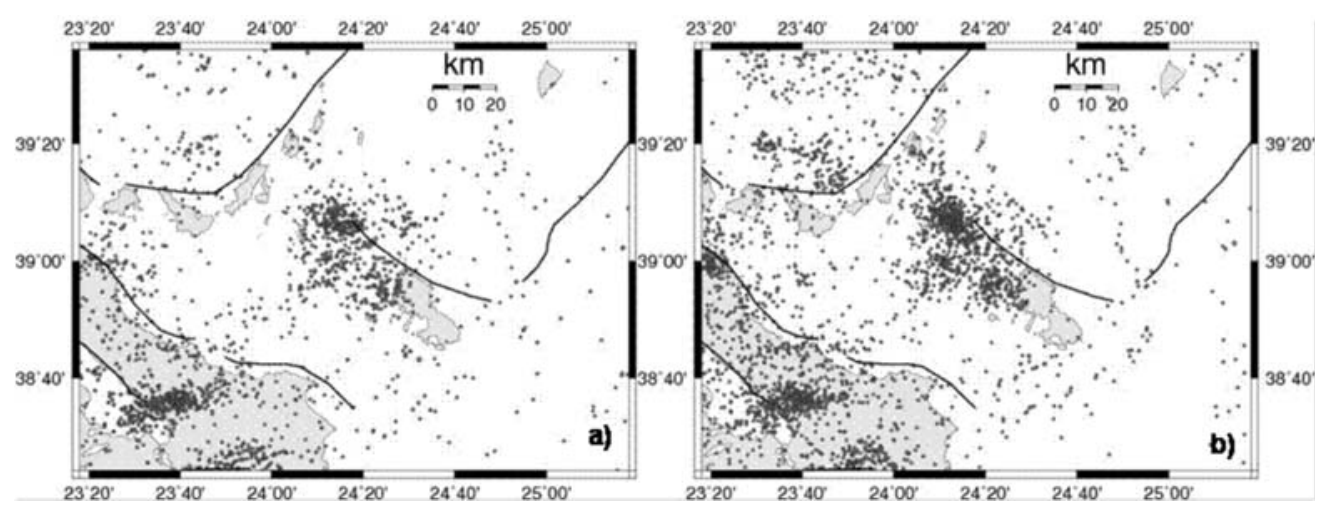

Fig. 5: a) Initial catalogue data of G.I-N.O.A b) Final Catalogue of unified homogenized data for Skyros region $(\mathrm{M} \geq 2.0)$.

that epicentres are concentrated in fault zones of NW-SE direction with a great cluster in Chalchidiki, in the normal faults that are located between Zervochoria and Arnaia, and a smaller cluster in the northern part of Thessaloniki-Gerakarou fault zone. The distribution of relocated events is in accordance with the seismotectonic regime of the area (Tranos et al.,2002) and the focal mechanisms that were determined by the University of Athens (S.L-U.o.A) and the Geodynamic Institute of the National Observatory of Athens (G.I-N.O.A).

Analyzing the aftershock sequence of Skyros earthquake (2001), the contribution of a relocated catalogue is clear (Fig. 6d). As in the example of Mygdonian basin, even here HYPOINVERSE contributes to a better located event catalogue. For the decade 1996-2006, 910 events of $\mathrm{M} \geq 2.0$ were located to the area north, north-west of Skyros Island. The mean rms obtained by HYPO71 in this case, was 0.6 seconds while the respective spatial errors by the $\mathrm{x}, \mathrm{y}$ and $\mathrm{z}$ axis were 2,5.3 and $3 \mathrm{~km}$. During the first relocation of hypocenters determined by HYPO71, the image gets clearer as it can be seen in Fig. $6 \mathrm{~b},(\mathrm{rms}=0.19 \mathrm{sec}, \mathrm{erx}=4 \mathrm{~km}$, ery $=4 \mathrm{~km}$, erz= $5.7 \mathrm{~km})$ while in the second step that relocation of HYPOINVERSE locations takes place (Fig. 6c), the differentiation of the clusters (Fig. $6 \mathrm{~d}$ ) and their connection to local faults is easier ( $\mathrm{rms}=0.13 \mathrm{sec}$, erx $=2.5 \mathrm{~km}$, ery=2.6 km, erz=3.5 km). According to Fig. 6d, what appears more likely to have happened in this case, is the activation of two major clusters of NW-SE direction and about 25 and $10 \mathrm{~km}$ length respectively, with possibly another, western of these two, $5 \mathrm{~km}$ long (Karakonstantis, 2009). These results are directly comparable with the respective ones of Benetatos et al. (2002) and Roumelioti et al. (2003) for the same region. All the solutions that came up with the relocation through HYPODD are in accordance with the focal mechanisms of the S.L-U.o.A and G.I-N.O.A for this time period.

The epicenter of the Athens Earthquake was located in Thriassion basin at a depth of $9.4 \mathrm{~km}$, obtained by the double-difference algorithm procedure. Out of 966 earthquakes of the aftershock sequence, with mean rms and spatial errors (erx, ery, erz) equal to $0.81 \mathrm{sec}, 3.4,4.1$ and $12.1 \mathrm{~km}, 823$ were relocated in a new location with the respective errors reduced to $0.12 \mathrm{sec}$ and $1.9,2.1$ and $2.6 \mathrm{~km}$ (erx, ery, erz). As it can be seen from Fig. 8c, using HYPOINVERSE a better concentration of events is achieved around main rupture zones than the respective of HYPO71 (Fig. 8a). After this process, the mean temporal residuals (rms) reached 0.36 seconds while the respective spatial ones were determined as 4.6, 5.1 and $18.2 \mathrm{~km}$ (erx, ery, erz). After the relocation (Fig. 8d), the mean temporal (rms) and spatial errors (erx, ery, erz) were reduced significantly. The mean rms value was equal to 0.06 seconds and mean erx, ery, erz reached $1.15,1.21,1.59 \mathrm{~km}$ respectively. The optimization of the final 


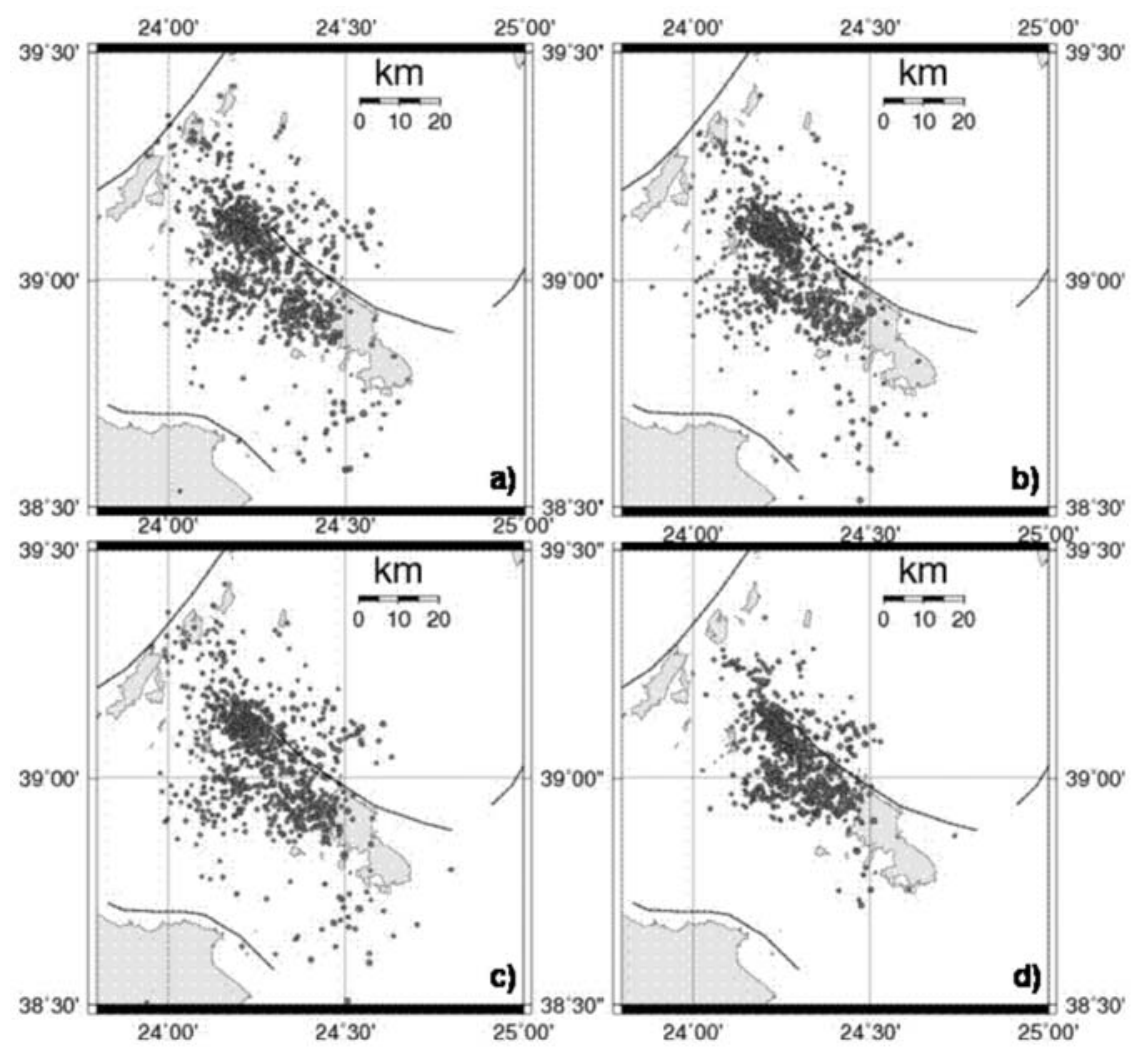

Fig. 6: a) Located earthquakes with HYPO71 b) Relocated data with HYPODD c) Located events with HYPOINVERSE d) Relocated events with HYPODD using a HYPOINVERSE processed primary catalogue $(\mathrm{M} \geq 2.0)$.

results leads to clustering of the earthquake sequence in two main parts. The first one is located WNW of the main shock epicenter while the second one is found eastern of it.

The distribution of epicenters in Fig. 8 b, d shows the activation of the Parnitha's fault escarpment. It is clear that the majority of aftershocks is located on a rectangular area around it (Karakonstantis, 2009) that extents along Thriassion basin with main direction WNW-ESE. It should be noted that the initially located events showed an important activity outside the fault area due to the large spatiotemporal errors. In addition a smaller cluster located NE of the epicentral area could be related to the Phyli's fault.

The earthquakes that occurred within 13 minutes before the main shock were located along the Parnitha fault, in the western cluster of the focal area, mainly at depths $11-14 \mathrm{~km}$, a clue that characterizes them as foreshocks.

The results of the aftershock distribution of the Athens earthquake were successfully compared with those obtained by Papadimitriou et al. (2002), where a local network had been set up to record the aftershock sequence (3.500 events). The existence of two main clusters is shown in the rose diagrams of azimuth and dip orientation distribution by Voulgaris et al. (2001) and in the focal mechanisms that were determined by Papadimitriou et al. (2000) in the area. 


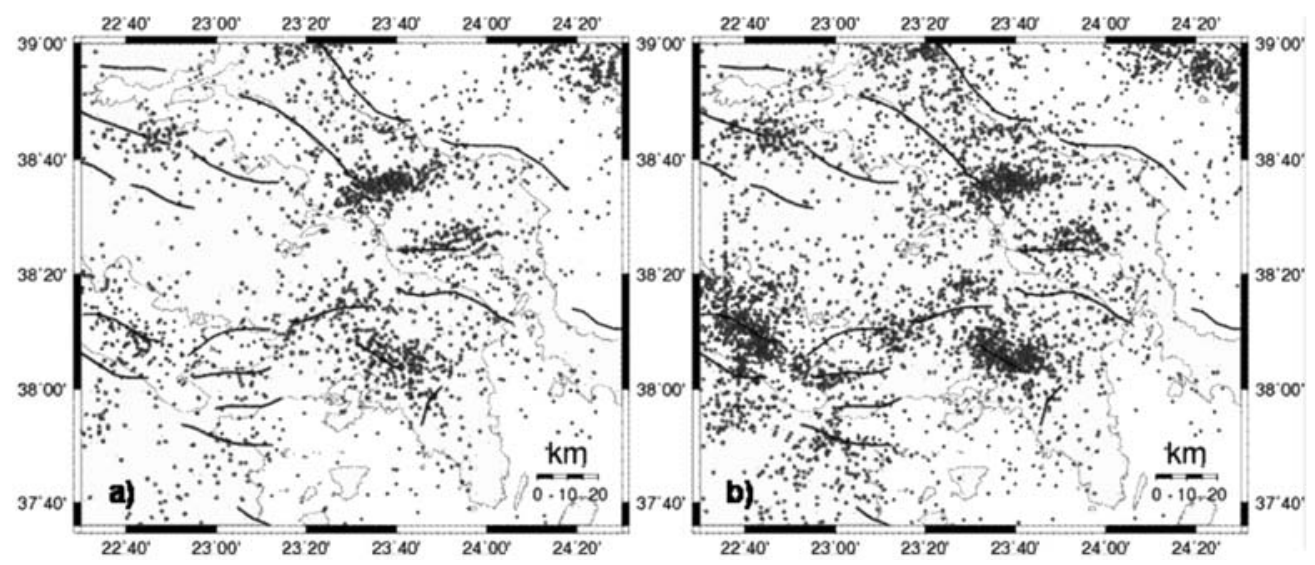

Fig. 7: a) Initial catalogue data of G.I-N.O.A b) Final Catalogue of unified homogenized data for Attica region $(\mathrm{M} \geq 2.0)$.

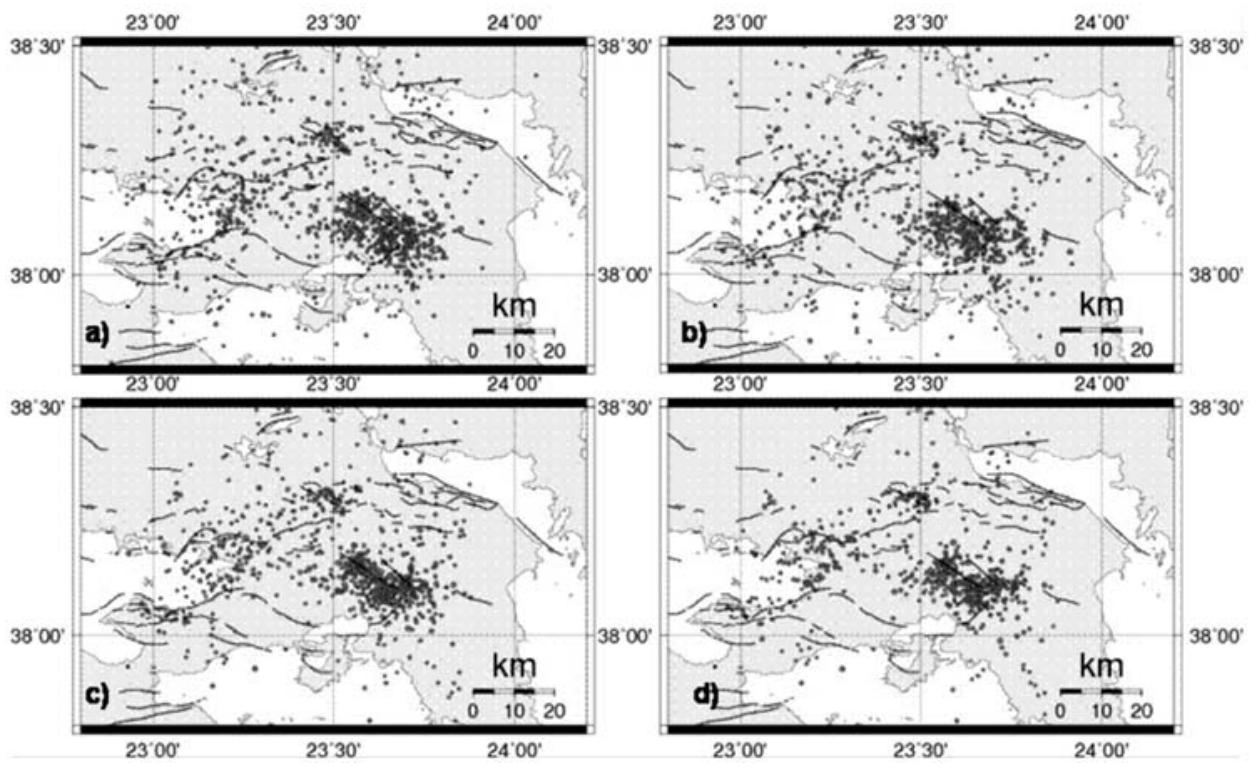

Fig. 8: a) Located earthquakes with HYPO71 b) Relocated data with HYPODD c) Located events with HYPOINVERSE d) Relocated events with HYPODD using a HYPOINVERSE processed primary catalogue $(\mathrm{M} \geq 2.0)$.

\section{Conclusions}

In this study the importance of using data from more than one permanent seismological network, as well as the need of using different algorithms in data processing to obtain better results was revealed.

During this study, data from three different catalogues were manually merged and processed by two different single-event location algorithms in order to achieve better locations and compare temporal and spatial residuals obtained by these two programs. In fact, some cases show that small spa- 
tial residuals don't necessarily mean a good location. That can be clearly seen by the qualitative comparison in certain cases, where HYPO71 spatial errors are smaller while the respective epicenters seem to be worse located than those of HYPOINVERSE. This process contributed to our effort to reveal more reliable spatial errors during the location step.

Phase data of the joint catalogue were used as an input file to HYPODD and by intervening in the parameters of the program we could achieve the optimization of the final result. In order to obtain better results it is necessary to have good primary epicenter locations and a more dense coverage of stations in the epicentral area. This task was achieved by merging and homogenizing the available data. Moreover, some relocated aftershock sequences, as the Athens and Skyros earthquakes, clearly reveal the dimension of the activated fault area. The mean spatial and temporal errors that were obtained through this procedure were minimized by up to one order of magnitude in areas with a dense coverage of stations by these three networks.

The results obtained by the double difference algorithm, in most cases, indicated a concentration of seismicity that in special cases was located along main rupture zones. Consequently they can be successfully compared to those obtained by available local networks that were deployed in the study area.

\section{References}

Benetatos, C., Roumelioti, Z., Kiratzi, A., Melis, N., 2002. Source parameters of the M 6.5 Skyros island (North Aegean Sea) earthquake of July 26, 2001. Ann. Geophys. 45, 513-526.

Karakonstantis, A., 2009. Unification-Homogenization of seismological catalogues and re-assessment of focal parameters of earthquakes during 1996-2006 period. Application to Seismotectonics of the Hellenic peninsula, Master thesis, National and Kapodistrian University of Athens, 262 pp.

Kaviris, I.G., 2003. Study of properties of the Eastern Corinth Gulf Seismic sources, PhD thesis, Athens 2003, pp.56-61, 74-84,238-241.

Papadimitriou, P., Kaviris, G,. Voulgaris, N., Kassaras, I., Delibasis N., and Makropoulos, K., 2000. Source Parameters Determination of the September 7, 1999 Athens Earthquake. Book of Abstracts, p. 33, XXVII ESC General Assembly, Lisbon, Portugal.

Papadimitriou, P., Voulgaris, N., Kassaras, I., Kaviris, G., Delibasis, N., Makropoulos, K., 2002. The $\mathrm{M}_{\mathrm{w}}=6.0,7$ September 1999 Athens Earthquake, Natural Hazards 27: p.15-33.

Roumelioti, Z., Kiratzi, A., Melis, N., 2003. Relocation of 26 July 2001 Skyros Island (Greece) earthquake sequence using the double-difference technique, Physics of the Earth and Planetary Interiors 138, pp.231-239.

Tranos, M. D.; Papadimitriou, E. E.; Kilias, A. A., 2002. Thessaloniki-Gerakarou Fault Zone (TGFZ): the western extension of the 1978 Thessaloniki earthquake fault (Northern Greece) and seismic hazard assessment, Journal of Structural Geology, v. 25, iss. 12, p. 2109-2123.

Voulgaris, N., Pirli, M., Papadimitriou, P., Kassaras, I. and Makropoulos, K., 2001. Seismotectonic Characteristics of the Area of Western Attica derived from the study of the September 7, 1999 Athens Earthquake Aftershock Sequence. Bull. Geol. Soc. of Greece, vol. XXXIV, no 4, p. 1645-1654.

Waldhauser, F., Ellsworth, W., 2000. A Double-Difference Earthquake Location Algorithm: Method and Application to the northern Hayward Fault, California, Bulletin of the Seismological Society of America 90,6, pp.1353-1368. 